\title{
Mortality of middle aged white South African gold
}

\section{miners}

\author{
C H WYNDHAM, ${ }^{1}$ B N BEZUIDENHOUT ${ }^{2}$ M J GREENACRE, ${ }^{3}$ \\ G K SLUIS-CREMER ${ }^{2}$ \\ From the Institute for Biostatistics of the South African Medical Research Council ${ }^{1}$ and the Epidemiology \\ Research Unit, Department of Health and Welfare, ${ }^{2}$ Johannesburg, and the Department of Statistics, ${ }^{3}$ \\ University of South Africa, Pretoria, Republic of South Africa
}

ABSTRACT A cohort of 3971 white miners in South Africa, born between 1 January 1916 and 31 December 1930 who were alive on 1 January 1970 and currently working in the East Rand-Central Rand-West Rand mining areas, was followed up for nine years, when the 3426 survivors were aged from 48 to 62 . Fifteen $(0.4 \%)$ had been lost to view and 530 had died $(13.4 \%$ of the 3956 whose vital status was determined). Based on the occupational histories of a $30 \%$ sample of the cohort it was known that the vast majority were gold miners. An estimated $93 \%$ had worked more than $85 \%$ of their mining service in gold mines. Standardised mortality ratios were calculated as the ratios of the deaths observed in the cohort to those expected on the basis of concurrent mortality in the reference population-the total white male population in the Republic of South Africa. There was little sign of a "healthy worker effect"; of several possible reasons, one is that the white miner in South Africa had adopted certain unhealthy life styles, another is that the reference population was otherwise inappropriate. The SMR for all causes of death (117.6) was raised because of excess mortality due to the following causes: lung cancer $(161 \cdot 2)$, chronic respiratory diseases (165.6), and acute and chronic nephritis (381.0). A case-referent analysis was carried out on those miners in the cohort who had spent at least $85 \%$ of their service in gold mines. For lung cancer, smoking was the main contributory factor towards disease. For chronic respiratory diseases (bronchitis, emphysema, asthma, pneumoconiosis, and pulmonary heart disease), smoking was also the main risk factor, but there was an association with cumulative dust exposure. Raised blood pressure, smoking, and adiposity were associated with ischaemic heart disease as was the duration of service underground. Study of comprehensive medical histories in all 530 deaths, including necropsy in most cases, showed that none was directly due to pneumoconiosis or to tuberculosis.

The mortality of workers in coal, asbestos, uranium, and certain base metal mines has been the subject of intense investigation in the past few decades, ${ }^{1-9}$ but we are aware of only one study which has included gold miners. ${ }^{10}$ In South Africa gold miners work in stressful conditions of heat and humidity and are exposed to low levels of dust containing a moderate amount of silica and to low levels of radon daughters. They are also exposed to unknown levels of other atmospheric pollutants, such as nitrous fumes from the blasting operations and exhaust fumes where diesel engines are used.

This two part study aimed to determine (1) whether

Accepted 3 March 1986 there was an excess mortality for certain diseases among middle aged white South African miners, most of whom were currently working on the goldmines in the East Rand, Central Rand, and West Rand gold mining regions of the Transvaal and (2) whether work in the gold mines contributed to the development of certain of these diseases. The first part was the calculation of standardised mortality ratios (SMRs) in a cohort of 3971 miners at work on 1 January 1970, followed up to the end of 1978 , using as a "reference" population, faute de mieux, the total white male population of the Republic of South Africa (RSA). The second part was a case-referent analysis, following Liddell et al, ${ }^{11}$ within the proportion of the same cohort who had had at least $85 \%$ of their service in gold mines and was concerned with deaths from lung 
cancer, chronic respiratory diseases, and ischaemic heart disease (IHD). These specific diseases were chosen for the case-referent analysis because there was reason to believe that service in the gold mines might contribute to the development of these diseases either due to the duration of underground service or to cumulative dust exposure.

\section{Subjects}

The target population was all white miners who, at the start of 1970, were aged 39 to 54 and had attended the Medical Bureau for Occupational Diseases (MBOD) in 1969. Most were currently working in gold mines in an area defined as the East RandCentral Rand-West Rand geographical region. These mines were all members of the Chamber of Mines (so that each man had a number in the Mining Provident Fund, which was to be an important source of information on vital status).

Every employee of any mine in the RSA who works underground or on the surface in specified "risk" occupations (defined by law on the basis of the degree of dust exposure) is legally required to present himself for an initial medical examination at the MBOD for a certificate of fitness for work in a risk occupation. The miner is also required to renew this certificate of fitness each year by a further medical examination. A miner may also request a "compensation examination" (see below), which is carried out at the MBOD. Those miners who were born between 1 January 1916 and 31 December 1930, who attended the MBOD in 1969, and who were known to be alive on 1 January 1979 , numbered 5062 . Of these, however, a total of 1092 did not meet the selection criteriaeither they worked for private contractors or for mines that were not members of the Chamber of Mines; they were not employed in 1970 in mines in the area defined above; or they had been referred to the MBOD from outside the designated area.

The remaining 3971 miners formed the study cohort. They are known (through estimates from Chamber of Mines records) to be such a high proportion of the men working in the defined area that enumeration must have been virtually complete.

White miners in the RSA are particularly mobile and a proportion of those in the cohort have, in addition to service in gold mines, had service in other types of mines. The objective in the case-referent analysis was to determine the effect of factors associated with service, primarily in gold mines, on three diseases of specific interest. For the purposes of this part of the study we used only subjects who had had at least $85 \%$ of their service in gold mines. The proportion of $85 \%$ was chosen because it indicated that each man had a major proportion of his service in gold mines and thus gave a more homogeneous sample, reducing possible bias due to service in other mines. A $30 \%$ sample of the 3971 miners indicated that the overwhelming majority (estimated at $93 \%$ ) had had more than $85 \%$ of their service in gold mines.

\section{Data collection}

It was possible to establish the vital status of all but 15 members of the cohort as at 31 December 1978-nine years from the date of entry into the cohort-mainly from the records of the Provident Fund but with some help from the Department of the Interior.

Death registration certificates of every person dying in the RSA are collected and filed by the Department of the Interior. Each year, they are submitted to the Central Statistical Services where coding clerks allocate to each certificate a rubric (code number) according to the International Classification of Diseases (ICD). The ICD code number is written on to the death registration certificate and it is then returned to the Department of the Interior for filing. In the period of the study the 8th revision of the ICD was used and the coding clerks followed the guidelines set out in the World Health Organisation manual for classifying causes of death and allocating code numbers.

Death registration certificates, with the ICD rubrics, were obtained from the Department of the Interior for all but two of the 530 deaths. (For the other two, abridged death certificates were obtained from the Provident Fund and the cause of death was ascertained; one had died in Botswana in a mine accident and the other in the RSA from coronary thrombosis.) The diagnoses recorded in the death registration certificates were used in the SMR analysis.

"Best available information" on the cause of each death was also assessed from the medical files at the MBOD and the records of the Provident Fund. This information has certain unique features. Firstly, 475 of the 530 miners who had died $(89.6 \%)$ had had a postmortem examination, although in a high proportion only the heart and lungs were examined. Secondly, every dead miner in the cohort had been examined, usually within a year of death, by a MBOD doctor. Thirdly, 33 of the 530 deceased miners had undergone a compensation examination in 1969. Such examinations are carried out by registered specialist physicians employed by MBOD in Johannesburg; these examinations are comprehensive and include an ECG recording and certain lung function tests. The diagnoses, according to the best available information, were used in the case-referent analysis.

It was possible to check the causes of death given on the death registration certification against the 
causes of death based on the best available information in the MBOD files. The results of this comparison are reported in the appendix.

Under the heading "chronic respiratory diseases" we have grouped together bronchitis, emphysema, and asthma (ICD 490-493), pneumoconiosis due to silica and silicates (515) or to other pneumoconiosis and other related diseases (516), and pulmonary heart disease (426) because examination of the MBOD files of those dead miners showed that none of the miners certified as dying from pneumoconiosis actually died from that disease. When pneumoconiosis was found in the miners, it was always an incidental finding in cases dying from some other cause, the most common of which was chronic obstructive lung disease. Similarly, when pulmonary heart disease appeared on the death certificate the cause of death was so coded, but examination of the MBOD files disclosed that in all of these cases there was associated chronic obstructive airways disease which was the primary cause of the pulmonary heart disease. Because of these inconsistencies between the causes of death, as classified by the Central Statistical Services, and the actual causes of death under this heading it was deemed to be more expedient to lump together all cases of death due to chronic respiratory diseases rather than subdivide the causes of death under separate, but often misleading, ICD rubrics.

\section{Methods of analysis}

\section{SUBJECT-YEARS METHOD}

The first analysis used the subject-years method ${ }^{12}$ to calculate the SMRs. Subject-years at risk during the study interval were calculated according to the technique of Hill. ${ }^{13}$ The choice of the reference population, the total white South African male population, was restricted by the availability of mortality figures and population estimates in the RSA. The Central Statistical Services for the RSA publish annual reports on the numbers of deaths by race, sex, age, and cause. On request, they provided mid-year population estimates for white South African men by quinquennial age groups for the nine single calendar years of the study interval. Age time cause specific death rates for the reference population were calculated from this material. From these rates, and from the relevant person-years in view during the study interval, the age cause specific expected numbers of deaths were found. The numbers of deaths observed, cause by cause, from the death registration certificate, were counted by age group and year. The observed $(O)$ and expected (E) deaths, by cause, were summed over each age group for the nine years of follow up, and the SMR was obtained as $100(\Sigma O) /(\Sigma E)$. Ninety five per cent confidence intervals for the SMRs were eval- uated under the usual assumptions, exploiting the link between the Poisson and $\chi^{2}$ distributions. ${ }^{14}$

From available records it would also have been possible to obtain complete histories of mining employment and information on smoking habits but it would have been prohibitively laborious to collect such details for the complete cohort. Thus there was no study of such factors within the first analysis.

\section{CASE-REFERENT ANALYSIS}

The second analysis was of the case-referent form, within the cohort, following Liddell et $a l^{11}$ for the three diseases of specific interest, lung cancer (42 deaths, according to the best available information), chronic respiratory diseases (29), and IHD (203).

For each case determined from the causes of death according to the best available information a set of referents was selected, strictly at random from among all those miners born in the same year as the case and who survived the case. No other matching for risk factors was performed. Four referents were selected for each death from lung cancer or chronic respiratory disease but, for practical reasons, only two referents were selected per case of IHD.

The proviso that each subject had had at least $85 \%$ of his service in gold mining reduced the number of deaths used in the analysis to $\mathbf{4 0}$ for lung cancer, 26 for chronic respiratory diseases, and 194 for IHD. For lung cancer and IHD we also considered it to be important to examine solely the effects of underground service on the risk of disease (see mining service below). By excluding men with service only in surface occupations, this further reduced the deaths in these specific analyses to 39 from lung cancer and 166 from IHD.

The following possible risk factors were investigated in the case referent analysis.

\section{Smoking}

Smoking was considered a risk factor for all three diseases. Smoking, which included cigarettes, cigars, or pipes smoked was converted to the number of cigarettes smoked per day using standard conversion factors. ${ }^{15}$ The amount smoked was recorded for the years 1960,1965, 1969, and the year of death of each case (or the same year for that case's referents). Since the amount smoked declined towards the cases' death it was decided to use the average of the amount smoked in 1960 and in 1965 as the variable to characterise smoking habits. If only one of these observations was available it was accepted; if neither was available the variable was regarded as missing.

\section{Mining service}

Two indicators of mining service were obtained: total years of underground service and particle years of 
cumulative dust exposure. The Chamber of Mines employment history records giving shifts worked by calendar period and occupation are available. Six occupational categories were identified according to the degree of dust experienced within these occupations. These included dusty occupations both on the surface of the mine and underground in the mine. The number of shifts worked extracted for all members of each case-referent set over the period from the date on which the subject's service started until either (for lung cancer and chronic respiratory diseases) the date of the case's last dusty shift worked or (for IHD) the case's last underground shift worked. The number of shifts was divided by 280 to obtain a measurement of mining service in "years."

Cumulative dust exposure (measured by thermal precipitator count of respirable particle sizes $0.5 \mu \mathrm{m}$ to $5 \mu \mathrm{m}$ before acid treatment) was computed by multiplying the length of time worked in any of the six occupational categories by a dust level index derived from the mean dust levels reported by Beadle. ${ }^{16}$

For lung cancer, the effect of both cumulative dust exposure and total years of underground service were analysed separately, the latter providing a surrogate measurement of the miner's lifetime exposure to the low levels of radon and its daughters found in South African gold mines. For chronic respiratory diseases the attributable factor considered was cumulative dust exposure. For IHD total years of underground service worked was the variable used to measure the effect of exposure to physical work in the hot and humid mines of the Witwatersrand, which might directly or indirectly be a risk factor for this disease.

\section{BLOOD PRESSURE AND QUETELET INDEX}

These two additional risk factors were considered for deaths from ischaemic heart disease. Systolic blood pressure measurements were recorded at the same four time points as for smoking. Blood pressure was calculated as the average of the two most recent recorded measurements before the death of the case. If only one observation was available it was accepted; if neither was available blood pressure was considered missing. For the Quetelet index, weight (W) had been recorded at the same four time points, but height $(\mathrm{H})$ was recorded only at the 1969 examination. We used the average of the two most recent weight measurements before death in the calculation of the index $\left(\mathrm{W} / \mathrm{H}^{2}\right)$.

To model the effects of these variables on the risk of disease, we used the RISK programme (DC Thomas, personal communication), which allows varying numbers of referents per case. Thus for a particular matched set comprising a case and four referents, if one referent had missing data for smoking, say, then he might be deleted from an analysis that includes amount smoked as a risk factor without dropping the matched set as a whole. Because data were matched sets, we used the option of programme RISK which maximises the conditional likelihood function to estimate the coefficients in the logistic regression model. ${ }^{17}$

\section{Results}

STANDARDISED MORTALITY RATIOS (SMRS)

Of the 3971 miners in the cohort, 15 were lost to viewo $(0.4 \%)$ and $3426(86.3 \%)$ survived into 1979. The deaths numbered 530, compared with 450.6 expectedô leading to an SMR of 117.6 substantially in excess of 100 .

Table 1 shows the observed numbers of deaths in the cohort from selected causes and the numbers expected, the SMRs, and the corresponding 95\% confidence intervals. Judged by these confidence intervals there was significant excess mortality, compared with the referent population of all white men in the RSA, for lung cancer, chronic respiratory

Table 1 SMRs for middle aged white gold miners in South Africa

\begin{tabular}{|c|c|c|c|c|c|}
\hline ICD code & Cause of death & $\begin{array}{l}\text { Observed } \\
\text { deaths }\end{array}$ & $\begin{array}{l}\text { Expected } \\
\text { deaths }\end{array}$ & $S M R$ & $\begin{array}{l}95 \% \text { Confidence } \\
\text { interval }\end{array}$ \\
\hline $\begin{array}{l}010-9 \\
151 \\
162 \\
410-4 \\
430-8 \\
480-6 \\
490-3,426,515-6 \\
571,578 \\
580-4 \\
790-6 \\
810-9 \\
950-9,979 \\
800-999 \text { LESS: } 937 \\
810-9,950-9,979 \\
\text { Rest }\end{array}$ & $\begin{array}{l}\text { Tuberculosis } \\
\text { Stomach cancer } \\
\text { Lung cancer } \\
\text { Ischaemic heart disease } \\
\text { Cerebrovascular disease } \\
\text { Pneumonias } \\
\text { Chronic respiratory diseases } \\
\text { Cirrhosis of the liver } \\
\text { Nephritis } \\
\text { Ill defined diseases } \\
\text { Motor vehicle accidents } \\
\text { Suicides } \\
\text { Accidents other than mine accidents, } \\
\text { motor vehicle accidents, and suicides } \\
\text { All other causes }\end{array}$ & $\begin{array}{r}4 \\
11 \\
39 \\
203 \\
23 \\
13 \\
26 \\
19 \\
8 \\
16 \\
16 \\
23 \\
18 \\
111\end{array}$ & $\begin{array}{r}2 \cdot 6 \\
7 \cdot 0 \\
24 \cdot 2 \\
176 \cdot 6 \\
25 \cdot 9 \\
15 \cdot 6 \\
15 \cdot 7 \\
11 \cdot 5 \\
2 \cdot 1 \\
12 \cdot 4 \\
18 \cdot 5 \\
14 \cdot 8 \\
16 \cdot 6 \\
107 \cdot 1\end{array}$ & $\begin{array}{r}153 \cdot 8 \\
157 \cdot 1 \\
161 \cdot 2 \\
114 \cdot 9 \\
88 \cdot 8 \\
83 \cdot 3 \\
165 \cdot 6 \\
165 \cdot 2 \\
381 \cdot 0 \\
129 \cdot 0 \\
86 \cdot 5 \\
155 \cdot 4 \\
\\
108 \cdot 4 \\
103.6\end{array}$ & $\begin{array}{r}41 \cdot 9-394 \cdot 1 \\
78 \cdot 4-281 \cdot 3 \\
114 \cdot 6-220 \cdot 3 \\
99 \cdot 7-131 \cdot 9 \\
56 \cdot 3-133 \cdot 3 \\
44 \cdot 4-142 \cdot 5 \\
108 \cdot 2-242 \cdot 7 \\
99 \cdot 4-258 \cdot 0 \\
164.4-750 \cdot 9 \\
73 \cdot 7-209 \cdot 6 \\
49 \cdot 4-140 \cdot 5 \\
98 \cdot 5-233 \cdot 2 \\
\\
64 \cdot 2-171 \cdot 4 \\
85.3-124.8\end{array}$ \\
\hline
\end{tabular}


disease, and acute and chronic nephritis. An excess mortality was also observed in the cases of IHD, cirrhosis of the liver, and suicide, but they were significant only at the $90 \%$ level. It must be made clear that the SMRs are based on the causes of death given on the death certificates in order to make valid comparisons with the deaths in the reference population.

\section{CASE-REFERENT ANALYSIS}

As the objective of the study was to assess the effect of mining service towards the risk of disease, the effects of the non-mining risk factors: amount smoked (for all three diseases considered), blood pressure, and Quetelet index of adiposity (for IHD only), were eliminated by entering them into the model before entering the variable for measuring mining service. The (pairwise) interactions between the respective covariates have not been reported here. Their inclusion in the model after entering mining service does not further the objective of our study as we have not attempted to formulate a mathematical model for risk factors on disease.

Every case of lung cancer and of chronic respiratory disease was a smoker. Nevertheless, we retained amount smoked as a continuous variable in the analyses for these two diseases.

\section{LUNG CANCER}

Two analyses were performed to assess separately the effect of cumulative dust exposure and years of underground service respectively on risk of disease, after eliminating the effect of amount smoked. In the first analysis (table 2) the amount smoked was a highly significant risk factor, with an estimated (multi- plicative) effect on the relative risk of 3.9 per 20 cigarettes a day. The likelihood ratio chi-square (henceforth abbreviated as $\operatorname{LR} \chi^{2}$, with one degree of freedom unless specified otherwise) has a value of $13.92(p=0.0002)$. The additional effect of cumulative dust exposure on relative risk was 1.77 per 10 units (particle years), but the additional chi-square contribution to the model was low $\left(\operatorname{LR} \chi^{2}=3.42\right.$, $\mathrm{p}=0.06$ ). The $95 \%$ confidence intervals for relative risks are also reported in table 2 . In the second analysis one case and his respective referents were excluded since the case had no underground service (see methods of analysis). Amount smoked was still highly significant (table 2), but the additional effect of years of underground service on relative risk, estimated as 1.14 per 10 years of service, was not significant $\left(\operatorname{LR} \chi^{2}=0.2, p=0.65\right)$. No cases or referents had any exposure to asbestos.

\section{CHRONIC RESPIRATORY DISEASES}

Amount smoked was again the major risk factor for disease, with an estimated effect on relative risk of 3.67 per 20 cigarettes smoked a day $\left(\operatorname{LR} \chi^{2}=7.04\right.$, $\mathrm{p}=0.008$ ). Cumulative dust exposure then had an additional effect on risk of disease estimated as 2.48 per 10 units $\left(\operatorname{LR} \chi^{2}=4.51, p=0.03\right)$.

\section{ISCHAEMIC HEART DISEASE}

The non-mining variables blood pressure, amount smoked, and Quetelet index were entered into the model in a stepwise manner by forward selection. Blood pressure emerged as the most significant risk factor in a statistical sense, with an estimated effect on relative risk of 1.31 per $10 \mathrm{~mm} \mathrm{Hg}\left(\operatorname{LR} \chi^{2}=12.36\right.$, $\mathrm{p}=0.0004$ ). Amount smoked followed, with an esti-

Table 2 Risk factors for lung cancer, chronic respiratory diseases, and ischaemic heart disease

\begin{tabular}{|c|c|c|c|c|}
\hline & \multicolumn{2}{|l|}{ Lung cancer } & \multirow{2}{*}{$\begin{array}{l}\text { Chronic } \\
\text { respiratory disease }\end{array}$} & \multirow{2}{*}{$\begin{array}{l}\text { Ischaemic } \\
\text { heart disease }\end{array}$} \\
\hline & Analysis 1 & Analysis 2 & & \\
\hline No of cases & 40 & 39 & 26 & 166 \\
\hline \multicolumn{2}{|c|}{ Relative risks (with $95 \%$ confidence intervals) of stated increases } & - & - & 1.31 \\
\hline $\begin{array}{r}\text { (10 mm Hg) } \\
\text { Quetelet index } \\
\left(10 \mathrm{~kg} \mathrm{~m}^{-2}\right)\end{array}$ & - & - & - & $\begin{array}{l}(1 \cdot 12-1 \cdot 33) \\
1.03 \\
(1.01-1 \cdot 05)\end{array}$ \\
\hline $\begin{array}{l}\text { Amount smoked } \\
\text { (20 cigarettes a day) }\end{array}$ & $\begin{array}{l}3.90 \\
(1.85-8.21)\end{array}$ & $\begin{array}{l}3 \cdot 74 \\
(1 \cdot 71-8 \cdot 20)\end{array}$ & $\begin{array}{l}3.67 \\
(1.43-9 \cdot 40)\end{array}$ & $\begin{array}{l}1 \cdot 72 \\
(1 \cdot 16-2 \cdot 54)\end{array}$ \\
\hline $\begin{array}{l}\text { Cumulative dust exposure } \\
\text { (10 (particle) years) }\end{array}$ & $\begin{array}{l}1.77 \\
(0.94-3.31)\end{array}$ & - & $\begin{array}{l}2.48 \\
(1.03-6.00)\end{array}$ & - \\
\hline $\begin{array}{l}\text { Underground service } \\
\text { (10 years) }\end{array}$ & - & $\begin{array}{l}1 \cdot 14 \\
(0.63-2.05)\end{array}$ & - & $(1.04-2.28)$ \\
\hline $\begin{array}{l}\text { Likelihood ratio chi-square } \\
\text { Non-mining risk factor(s) }\end{array}$ & $\begin{array}{l}\text { ignificant levels }) \\
13.92(1) \\
(\mathrm{p}=0.0002)\end{array}$ & $\begin{array}{l}12.95(1) \\
(p=0.0003)\end{array}$ & $\begin{array}{l}7.04(1) \\
(p=0.008)\end{array}$ & $\begin{array}{l}26 \cdot 57(3) \\
(p=0.000007)\end{array}$ \\
\hline $\begin{array}{l}\text { Mining risk factor, after } \\
\text { allowing for non-mining } \\
\text { factors }\end{array}$ & $\begin{array}{l}3.42(1) \\
(p=0.06)\end{array}$ & $\begin{array}{l}0.20(1) \\
(p=0.65)\end{array}$ & $\begin{array}{l}4.51(1) \\
(p=0.03)\end{array}$ & $\begin{array}{l}8 \cdot 17(1) \\
(p=0.004)\end{array}$ \\
\hline
\end{tabular}


mated effect of 1.72 per 20 cigarettes a day $\left(\mathrm{LR} \chi^{2}=9.89, \mathrm{p}=0.002\right)$; Quetelet index had an estimated effect of 1.03 per $10 \mathrm{~kg} \mathrm{~m}^{-2}\left(\mathrm{LR} \chi^{2}=4.32\right.$, $\mathrm{p}=0.04)$. As a set these three non-mining risk factors had a contribution to the $L R \chi^{2}$ of 26.57 $(p=0.000007,3$ degrees of freedom). The additional effect of underground service was then investigated by entering this variable into the model. The effect on relative risk per 10 years of service was estimated as 1.54 and is statistically significant $\left(\operatorname{LR} \chi^{2}=8 \cdot 17\right.$, $\mathrm{p}=0.004$ ).

\section{Discussion}

\section{REFERENCE FOR OBTAINING SMRS}

The reference population for obtaining the age-cause specific mortality details of the same sex and race, and over the relevant study intervals, was the total white male population in RSA. It was important that the proportion of Afrikaners in the general population $(60 \%)$ was similar to that in the cohort of miners $(63 \%)$ because Afrikaans men are known to have a higher rate of IHD than other white men in the RSA. ${ }^{18}$ The cohort of miners differed from the reference population in that each miner, on engagement at the age of 17 or 18 , undergoes a medical examination that excludes men with certain overt diseases and those who are grossly overweight and underweight.

On these grounds we expected a pronounced healthy worker effect in our SMR analysis as has been the case in many other SMR studies of industrial workers, including miners. To our surprise, however, the SMR for all causes of death of this cohort of miners was 117.6 which is substantially above 100 . One possible explanation for this result is that the reference population was inappropriate; corresponding problems have been discussed by $\mathrm{McMichael}^{19}$ and Hernberg $^{20}$ inter alia. Another explanation is that this cohort of miners was actually less healthy than men of the same age in the general population. There is support for this proposal in the fact that of the 79 miners' deaths in excess of those expected, 26 were due to ischaemic heart disease, 15 to lung cancer, 10 to chronic respiratory disease, eight to suicide, and seven to cirrhosis of the liver. Thus $66(83 \%)$ of the excess deaths could be attributed to certain aspects of life styles which are known to be destructive to health such as dietary excesses, smoking, and excessive alcohol intake. Whether the white miner in the RSA is more liable to these unhealthy life styles than the general white male population needs further investigation. The possibility that the reference population was otherwise inappropriate and that the SMRs for specific causes of death must be treated with caution cannot be dismissed, however.
MORTALITY FROM SELECTED CAUSES OF DEATH What emerges from published reports on lung cancer among miners is that coal miners do not suffer excess mortality from lung cancer ${ }^{121-23}$ but hard rockminers may-excesses have been shown in metal, ${ }^{78}$ tin, ${ }^{9}$ and gold mining. ${ }^{10}$ Pollution of the mine atmosphere has been suggested as a possible causal factor. Radon and its daughters are such agents; they are emitted from hard rock but concentrations in mine atmospheres have been low, except in uranium mines. From a study in the underground atmospheres of goldmines in South Africa from 1960 to $1967,{ }^{24}$ it was estimated that the average working level months (WLM) was $35.8 \pm 0.4$, in the same order as the radiation exposures in Cornish tin mines of 15 to 25 WLMs $^{9}$ and in the goldmines of Western Australia of about 16 WLMs. ${ }^{10}$ These levels should be seen in the context of the radiation exposures, varying between 120 and 3700 WLMs, of miners in United States uranium mines in the 1960s, in which there was a considerable excess of lung cancer. ${ }^{5}$

The cardinal role of smoking in the excess mortality from lung cancer in the cohort is clear from the casereferent analysis. As this analysis showed an association of risk with cumulative dust exposure at a low level of statistical significance $(p=0.06)$ and a nonsignificant association with duration of underground service, it is likely that neither exposure to radon nor exposure to silica contribute to the excess of lung can cer. No arsenic is found in the Witwatersrand gold mines.

The excess mortality due to chronic respiratory diseases is not surprising. Both cigarette smoking and exposure to dust in mines are causal factors of chronic respiratory diseases. ${ }^{1525}$ The case-referent analysis indicated that amount smoked was of much greater importance than cumulative dust exposure, which itself was a significant risk factor $(p=0.03)$ in the case of chronic respiratory diseases.

The excess mortality from ischaemic heart disease in our study was unexpected. Costello et al failed to find an excess mortality for IHD among coal miners in the United States. ${ }^{26}$ They did, however, find an excess IHD mortality in a subgroup of their coal miners who both smoked and were obese. A not unexpected finding in our case-referent analysis was the significant relation between mortality for IHD and the non-mining risk factors of hypertension, smoking, and the Quetelet index of adiposity. Our main objective, however, was to examine the possibility that duration of underground service was an additional risk factor for IHD in the presence of these confounding factors. When the effects of these nonmining risk factors were eliminated in the statistical analysis there was indeed a significant relation $(p=0.004)$ between the duration of underground ser- 
vice in the gold mines and mortality from IHD. A significant association between IHD and duration of underground service has not, as far as we are aware, been found previously.

A surprisingly high proportion $(43.5 \%)$ of the 23 suicides were due to carbon monoxide poisoning from motor vehicle exhausts compared with $20.4 \%$ of suicides in the reference population. The apparent excess for cirrhosis of the liver suggests that white miners in the RSA have a higher proportion of those who suffer from chronic alcoholism than the general population in the RSA of white men in this age group.

Finally, although deaths from acute and chronic nephritis were few, there were more than expected, which is consistent with previous findings. ${ }^{27}$

We are particularly grateful for advice and comments on earlier drafts from Professor F D K Liddell of the Department of Epidemiology and Biostatistics of McGill University, Canada. We also gratefully acknowledge the help of Dr F J Wiles, the director of the Medical Bureau for Occupational Diseases (MBOD), Johannesburg; the help in the initial phase of both Dr W P D Logan of Geneva and Professor F Lombard of the Department of Statistics of the University of South Africa; and Dr A T Halliday of the MBOD who helped to decide upon the causes of death on the best available information.

\section{Appendix}

COMPARISON OF CAUSES OF DEATH ON THE DEATH REGISTRATION CERTIFICATE AND ON

THE BEST AVAILABLE INFORMATION

The comparison of causes of death on the death registration certificate and on the best available information in the MBOD files is summarised in table 3. The third column gives the number of deaths for each of the causes of death in which the two sources were in agreement. For example 187 deaths certified as IHD on the death registration certificates were supported by the information in the MBOD files. Thus of the 203 deaths considered to be due to IHD on the best available information, in $92.1 \%$ the death registration certificates were also coded IHD.

It is encouraging that for most of the causes of death of interest there was close agreement between the cause coded on the death registration certificates and the cause based on the best available information. For chronic respiratory diseases, agreement was only as good as indicated because of the grouping as discussed in the text. Problems with the certification of tuberculosis and pneumoconiosis, however, are discussed here.

Tuberculosis was coded as the cause of death on the death certificate of four miners. Examination of
Table 3 Comparison of cause of death. (Figures in parentheses are numbers of death where cause was agreed, as percentage of numbers by cause on "best available information")

\begin{tabular}{|c|c|c|c|}
\hline \multirow[b]{2}{*}{ Causes of death } & \multicolumn{3}{|c|}{ No of deaths according to } \\
\hline & $\begin{array}{l}\text { Death } \\
\text { registration } \\
\text { certificate }\end{array}$ & $\begin{array}{l}\text { Best } \\
\text { available } \\
\text { information }\end{array}$ & Agreed \\
\hline $\begin{array}{l}\text { Ischaemic heart disease } \\
\text { Lung cancer } \\
\text { "Other" neoplasms }\end{array}$ & $\begin{array}{r}203 \\
39 \\
34\end{array}$ & $\begin{array}{r}203 \\
42 \\
40\end{array}$ & $\begin{array}{r}187(92 \cdot 1) \\
35(83 \cdot 3) \\
32(80 \cdot 0)\end{array}$ \\
\hline $\begin{array}{l}\text { Chronic respiratory } \\
\text { diseases } \\
\text { Suicides } \\
\text { Cerebrovascular disease } \\
\text { Cirrhosis of liver } \\
\text { Motor vehicle accidents } \\
\text { Mine accidents } \\
\text { "Other" accidents, }\end{array}$ & $\begin{array}{l}26 \\
23 \\
23 \\
19 \\
16 \\
14\end{array}$ & $\begin{array}{l}29 \\
24 \\
20 \\
20 \\
19 \\
15\end{array}$ & $\begin{array}{l}21(72.4) \\
22(91 \cdot 7) \\
19(95 \cdot 0) \\
17(85.0) \\
16(84 \cdot 2) \\
14(93 \cdot 3)\end{array}$ \\
\hline $\begin{array}{l}\text { poisoning, and violence } \\
\text { Stomach cancer } \\
\text { Ill defined diseases } \\
\text { Tuberculosis } \\
\text { Other known causes } \\
\text { Total }\end{array}$ & $\begin{array}{r}16 \\
11 \\
16 \\
4 \\
86 \\
530\end{array}$ & $\begin{array}{r}18 \\
13 \\
4 \\
0 \\
83 \\
530\end{array}$ & $\begin{array}{c}14(77 \cdot 8) \\
10(76 \cdot 9) \\
0(0) \\
0(0) \\
58(70 \cdot 7) \\
445(84.0)\end{array}$ \\
\hline
\end{tabular}

the MBOD files showed that in only one of these four had tuberculosis been diagnosed during life. He had had an $x$ ray shadow which was investigated to distinguish between lung cancer and pulmonary tuberculosis. A bronchial washing showed tubercle bacilli. After treatment he made a complete recovery and eventually died of mitral valve disease with congestive cardiac failure. The actual causes of death of the other three dead miners on the best available information were: (1) cancer of the lung (confirmed histologically); (2) coronary thrombosis (with an antemortem thrombus in the right coronary artery); and (3) pulmonary embolus (with an antemortem thrombus in a pulmonary artery).

Pneumoconiosis was coded as the cause of death of four miners. Two had clear evidence of severe chronic obstructive lung disease with a forced expiratory ventilation in one second $\left(\mathrm{FEV}_{1}\right)$ less than $40 \%$ of normal. Of the other two cases, one died from diffuse scleroderma and the other from Goodpasture's syndrome-at necropsy there was massive intraalveolar haemorrhage and foci of interstitial fibrosis. Silicosis was found only in microscopic sections of lung tissue and thus was clearly an incidental finding and not the cause of death.

The finding of most immediate importance to the mining industry is that, based on the best available information, not one of these 530 miners died either from tuberculosis or pneumoconiosis due to silica dust. This confirms the impression of the clinicians at the MBOD that, today, these two conditions hardly ever cause death among middle aged white South African miners. Agreement was also close for most 
causes of death but was non-existent for tuberculosis and ill-defined diseases.

Correspondence: Professor C H Wyndham, Box 17555, Hillbrow, Johannesburg 2038.

\section{References}

1 Liddell FDK. Mortality of British coal miners in 1961. Br J Ind Med 1973;30:15-24.

2 Ortmeyer CE, Costello J, Morgan WKC. The mortality of Appalachian coal miners, 1963-71. Arch Environ Health 1974;29:67-72.

3 Rockette HE. Cause specific mortality of coal miners. J Occup Med 1977;19:795-801.

4 McDonald JC, Liddell FDK, Gibbs GW, et al. Dust exposure and mortality in crysotile mining, 1910-75. Br J Ind Med 1980;37:11-24.

5 Wagoner JK, Archer VE, Lundin FE, et al. Radiation as the cause of lung cancer among uranium miners. $N$ Engl $J$ Med 1965;273:181-8.

6 Wagoner JK, Miller RW, Lundin FE, et al. Unusual cancer mortality in a group of underground metal workers. $N$ Engl J Med 1963;269:284-9.

7 Axelson $O$. Mining, lung cancer and smoking. Scand $J$ Work Environ Health 1978;4:46-52.

8 Boyd JT, Doll R, Faulde JS, et al. Cancer of lungs in iron ore (haematite) miners. Br J Ind Med 1970;27:97-105.

9 Fox AJ, Goldblatt PO, Kinlem LI. A study of the mortality of Cornish tin miners. Br J Ind Med 1981;38:378-83.

10 Armstrong BK, McNulty JC, Levitt LJ, et al. Mortality in gold and coal miners in Western Australia with special reference to lung cancer. Br J Ind Med 1979;36:199-205.

11 Liddell FDK, McDonald JC, Thomas DC. Methods of cohort analysis: appraisal by application to asbestos mining. Journal of the Royal Statistical Society 1977;140:469-91.
Wyndham, Bezuidenhout, Greenacre, Sluis-Cremer

12 Berry $G$. The analysis of mortality by the subject-years method. Biometrics 1983;39:173-84.

13 Hill ID. Computing man years at risk. Br J Prev Soc Med 1972;26:132-4.

14 Liddell FDK. Simple exact analysis of the standardised mortality ratio. J Epidemiol Community Health 1984;38:85-8.

15 Sluis-Cremer GK, Walters LG, Sichel HS. Chronic bronchitis in miners and non-miners: an epidemiological survey of a community in a gold mining area in the Transvaal. Br $J$ Ind Med 1967;24:1-12.

16 Page-Shipp RJ, Harris E. A study of the dust exposure of South African white gold miners. Journal of the $S$ African Institute of Minerals and Metallurgy 1972;73:10-23.

17 Breslow NE, Day NE. Statistical methods in cancer research I. The analysis of case-control studies. Lyon: International Agency for Research on Cancer, 1980:248-79.

18 Pretorius JPG. High ischaemic heart disease mortality among young Afrikaners. SA Med J 1983;64:427-9.

19 McMichael AJ. Standardised mortality ratios and the "healthy worker effect"; scratching beneath the surface. J Occup Med 1976;18:165-8.

20 Hernberg S. Fact and fiction in occupational mortality. $J$ R Coll Physicians 1983;17:139-43.

21 Kennaway NM, Kennaway EL. A study of the incidence of cancer of the lung and larynx. J Hyg 1936;36:236-67.

22 Goldman KP. Mortality of coal miners from carcinoma of the lung. $B r J$ Ind Med 1965;22:72-7.

23 Costello J, Ortmeyer CE, Morgan WKC. Mortality from lung cancer in US coal miners. Am J Public Health 1974;64:222-4.

24 Wyndham CH, Heyns AJ, Keeley WH, et al. Lung cancer rates among white South African miners. Johannesburg: Chamber of Mines, 1970. (Internal COM research report No 23/70.)

25 Wiles FJ, Faure MH. Chronic obstructive lung disease in gold miners. In: Walton WH, ed. Inhaled particles IV. Part 2. Oxford: Pergamon Press, 1977:727-35.

26 Costello J, Ortmeyer CE, Morgan WKC. Mortality from heare disease in coal miners. Chest 1975;67:417-21.

27 Thun M, Stayner L, Brown D, et al. Mining and deaths from chronic renal failure. Lancet 1982;ii:606.

\section{Correspondence and editorials}

The British Journal of Industrial Medicine welcomes correspondence relating to any of the material appearing in the journal. Results from preliminary or small scale studies may also be published in the correspondence column if this seems appropriate. Letters should be not more than 500 words in length and contain a minimum of references. Tables and figures should be kept to an absolute minimum. Letters are accepted on the understanding that they may be subject to editorial revision and shortening.

The journal now also publishes editorials which are normally specially commissioned. The Editor welcomes suggestions regarding suitable topics; those wishing to submit an editorial, however, should do so only after discussion with the Editor. 